\title{
HER3 protein expression as a risk factor for post-operative recurrence in patients with early-stage adenocarcinoma and adenosquamous carcinoma of the cervix
}

\author{
TAKAAKI MIZUNO ${ }^{1,2}$, YUKI KOJIMA ${ }^{1}$, KAN YONEMORI ${ }^{1}$, HIROSHI YOSHIDA ${ }^{3}$, YUKIKO SUGIURA ${ }^{4}$, \\ YOHEI OHTAKE ${ }^{1}$, HITOMI S. OKUMA ${ }^{1}$, TADAAKI NISHIKAWA ${ }^{1}$, MAKI TANIOKA ${ }^{1}$, KAZUKI SUDO ${ }^{1}$, \\ AKIHIKO SHIMOMURA ${ }^{1}$, EMI NOGUCHI ${ }^{1}$, TOMOYASU KATO ${ }^{4}$, TATSUNORI SHIMOI ${ }^{1}$, MASAYA UNO $^{4}$, \\ MITSUYA ISHIKAWA ${ }^{4}$, YASUHIRO FUJIWARA ${ }^{1}$, YUICHIRO OHE ${ }^{2}$ and KENJI TAMURA ${ }^{1}$ \\ ${ }^{1}$ Department of Breast and Medical Oncology, National Cancer Center Hospital, Tokyo 104-0045; \\ ${ }^{2}$ Cancer Medicine, Jikei University Graduate School of Medicine, Tokyo 105-8461; \\ Departments of ${ }^{3}$ Pathology and ${ }^{4}$ Gynecology, National Cancer Center Hospital, Tokyo 104-0045, Japan
}

Received February 22, 2020; Accepted June 19, 2020

DOI: $10.3892 / 01.2020 .11899$

\begin{abstract}
Patients with cervical adenocarcinoma (AC) and adenosquamous carcinoma (ASC) have a poorer prognosis than those with squamous cell carcinoma (SCC). Erb-b2 receptor tyrosine kinase 3 (HER3) is a member of the epidermal growth factor receptor family and its expression is associated with unfavorable prognosis in several cancer types, including SCC of the cervix. As there is limited information on the prognostic value of HER3 for AC and ASC of the cervix, the present study aimed to evaluate the expression of HER3 and its impact on post-operative recurrence in patients with $\mathrm{AC}$ and ASC of the cervix. This retrospective study included 39 patients with early-stage AC and ASC who underwent primary surgery between January 1997 and December 2017. Immunohistochemical staining for HER3 was performed on formalin-fixed paraffin-embedded surgical specimens. The possible influence of HER 3 expression on disease-free survival (DFS) was studied by using multivariate Cox regression with adjustment for established risk factors of post-operative recurrence. High expression of HER3 (HER3-high) was detected in $85.1 \%$ of cases of AC (23/27) and in 58.3\% of cases of ASC (7/12). The median follow-up duration was 63.1 months and Kaplan-Meier analysis indicated that the 5-year DFS rates of patients with AC and ASC of the cervix were $56.7 \%$ in patients with HER3-high and 77.8\% in patients with HER3-low (log rank, $\mathrm{P}=0.20$ ). On multivariate analysis, HER3-high [hazard ratio $(\mathrm{HR})=6.32,95 \% \mathrm{CI}: 1.10-36.26, \mathrm{P}=0.039)$, pelvic lymph
\end{abstract}

Correspondence to: Dr Kan Yonemori, Department of Breast and Medical Oncology, National Cancer Center Hospital, Tsukiji 5-1-1, Chuo-ku, Tokyo 104-0045, Japan E-mail: kyonemor@ncc.go.jp

Key words: HER3 protein expression, cervical cancer, prognostic factor, biomarker node metastasis (HR=7.61, 95\% CI: 2.07-28.00, $\mathrm{P}=0.002)$ and vascular invasion $(\mathrm{HR}=4.28,95 \% \mathrm{CI}: 1.12-16.31, \mathrm{P}=0.033)$ were indicated to be independent predictors of DFS. To date, the present study is the most comprehensive analysis to evaluate the expression of HER 3 in patients with early-stage AC and ASC of the cervix. The results suggested that HER3 overexpression may be an independent risk factor for post-operative recurrence. However, these results and the prognostic value of HER3 should be confirmed in a larger sample.

\section{Introduction}

Cervical cancer is the fourth most common cancer type among females worldwide, with $>500,000$ new cases diagnosed in 2018; 11,000 patients are diagnosed and $\sim 3,000$ patients die annually in Japan $(1,2)$. Although squamous cell carcinoma continues to be the most frequent pathological type, the incidence of cervical adenocarcinoma (AC) and adenosquamous carcinoma (ASC) has increased in several countries (3-5). AC and ASC of the uterine cervix accounted for $15-25 \%$ of all cases of cervical cancer $(3,5)$ and the affected patients were younger than those with squamous cell carcinoma (SCC) (5).

The prognosis of patients with AC and ASC has been evaluated in several studies, but the results remain controversial (6-18). Certain studies have indicated that the prognosis of AC and ASC is worse than that of SCC, while others reported a similar prognosis. In addition, AC and ASC are less radiosensitive than SCC $(16,19)$. Hence, it remains elusive whether the treatment strategy used for SCC may be adopted for patients with AC and ASC. Therefore, the factors associated with the prognosis of AC and ASC and the biomarkers targetable with molecular targeted drugs require investigation.

Erb-b2 receptor tyrosine kinase 3 (HER3) is a member of the epidermal growth factor receptor (EGFR) family and is a cell-surface receptor tyrosine kinase (20). HER3 overexpression is associated with unfavorable prognosis in several cancer types (21). Although the incidence of HER3 overexpression ranged from 55.6 to $74.4 \%$ among cases of SCC of the cervix 
and HER3 was indicated to be a poor prognostic factor, information regarding the expression of HER3 in cases of $\mathrm{AC}$ and ASC of the cervix and whether it is a prognostic factor remains limited $(22,23)$. Therefore, the present study aimed to evaluate the expression of HER3 and its significance in the post-operative recurrence in patients with AC and ASC of the cervix.

\section{Patients and methods}

Patients and specimens. The medical records of patients with cervical cancer who were diagnosed and treated at the National Cancer Center Hospital (Tokyo, Japan), between January 1997 and December 2017 were retrospectively analyzed. Patients included in the present study fulfilled the following inclusion criteria: i) Pathological diagnosis of AC and ASC of the cervix, ii) early-stage disease [International Federation of Gynecology and Obstetrics (FIGO) stages I and II] and iii) availability of sufficient formalin-fixed paraffin-embedded surgical specimens for immunohistochemical staining and analysis (24).

Specimens of 39 cases of $\mathrm{AC}(\mathrm{n}=27)$ and $\mathrm{ASC}(\mathrm{n}=12)$ of the cervix obtained via surgical resection were retrieved from the pathology database of the National Cancer Center Hospital (Tokyo, Japan). The histological type was based on the World Health Organization classification of tumors of the uterine cervix (4th edition) (25). The medical records of all the identified patients were evaluated to obtain the following information: Age, performance status at diagnosis, FIGO clinical stage, date of treatment initiation, date of surgery, date of radiotherapy, the administered chemotherapy regimen, date of progression, date of the last follow-up and survival status. The protocol for the human study was reviewed and approved by the ethics committee of the National Cancer Center Hospital (Tokyo, Japan; no. 2014-393). Written informed consent was obtained from all of the participants.

Immunohistochemical staining and analysis. Hematoxylin and eosin (H\&E)-stained slides from each of the cases were reviewed to obtain representative sections. New 4- $\mu \mathrm{m}$-thick sections were prepared from formalin-fixed paraffin-embedded surgical specimens and were immunohistochemically stained. After deparaffinization, the expression of HER3 was determined by immunohistochemistry using a rabbit monoclonal antibody against HER3 (1:59 dilution; clone D22C5; Cell Signaling Technology, Inc.). Antigen retrieval was achieved by using a PT Link machine (Dako) at high $\mathrm{pH}$. Immunohistochemistry staining was performed using the Dako autostainer Link48 (Dako) and EnVision Flex Mini kit (Dako), according to the manufacturer's protocols. The slides were counterstained with hematoxylin.

HER3 expression was evaluated by an experienced pathologist in accordance with the HER2 testing guidelines for gastroesophageal cancer from the College of American Pathologists, American Society for Clinical Pathology and American Society of Clinical Oncology (26). High HER3 expression (HER3-high) was defined as a score of $2+$ or $3+$ and low HER3 expression (HER3-low) was defined as a score of 0 or $1+$. Immunohistochemical staining of p16 (clone INK4, 1;10, BD Bioscience) was also performed for the representative tumor section of each case. The slides were evaluated by the pathologist with the cut-off for positivity $>70 \%$. The pathologist was blinded to the clinical data while evaluating the slides.

Statistical analysis. Disease-free survival (DFS) was defined as the time between the date of initial surgery to the date of documentation of relapse, including locoregional recurrence and/or distant metastasis or death from any cause. The absence of relapse or death was treated as a censored observation. Overall survival (OS) was defined as the time from the date of initial surgery to the date of death from any cause. Patients without such events were treated as censored observations. DFS and OS were estimated using the Kaplan-Meier method and survival curves were compared using the log-rank test. A possible influence of HER3 expression on survival was assessed by using univariate and multivariate Cox regression analyses with the forced entry method after adjustment for established risk factors of post-operative recurrence (27-29). A two-sided $\mathrm{P}<0.05$ was considered to indicate statistical significance. All statistical analyses were performed with EZR (Saitama Medical Center, Jichi Medical University) (30), which is a graphical user interface for $\mathrm{R}$ (The R Foundation for Statistical Computing).

\section{Results}

Patient characteristics. Of the 39 patients with stages Ib1-IIB included in the present study, 27 were histologically classified as AC and 12 as ASC. The demographic and clinicopathological characteristics of the patients are summarized in Table I. The study population included 39 patients with an age range of 32 to 67 years. The median age of the patients was 43 years. The clinical stage of the patients determined according to the FIGO staging system was stage IB1 in 25 patients, IB2 in 9 and IIB in 4 patients. Lymph node metastasis was present in $38.5 \%$ of patients. Expression of p16 was positive in $79.8 \%$ $(31 / 39)$ of all cases, $70.4 \%(19 / 27)$ of cases of AC and $100.0 \%$ $(12 / 12)$ of cases of ASC.

Immunohistochemistry staining for HER3 expression in AC and ACC of the cervix. HER3 expression was determined in the surgical specimens from 39 patients with AC and ASC of the cervix using immunohistochemistry. Membranous HER3 overexpression was evaluated according to the criteria described above and representative images are provided in Fig. 1. High expression of HER3 (HER3-high) was determined in $85.1 \%(23 / 27)$ of cases of $\mathrm{AC}$ and in $58.3 \%(7 / 12)$ of cases of ASC (Table II).

Association of HER3 expression with outcomes. During the median follow-up of 63.1 months, the 5-year DFS rates in patients with $\mathrm{AC}$ and ASC of the cervix were $56.7 \%$ among patients with HER3-high and $77.8 \%$ among patients with HER3-low (log-rank $\mathrm{P}=0.20$; Fig 2A). The 5-year OS rates were $83.3 \%$ among patients with HER3-high and $100.0 \%$ among patients with HER3-low (log-rank $\mathrm{P}=0.22$; Fig 2B). Multivariate logistic regression analysis with the Cox proportional hazards model revealed that HER3-high [hazard ratio $(\mathrm{HR})=6.32,95 \% \mathrm{CI}: 1.10-36.26, \mathrm{P}=0.039)$, pelvic lymph node metastasis $(\mathrm{HR}=7.61,95 \% \mathrm{CI}: 2.07-28.00, \mathrm{P}=0.002)$ and 
Table I. Patient characteristics.

\begin{tabular}{|c|c|c|c|}
\hline \multirow[b]{2}{*}{ Parameter } & \multicolumn{2}{|c|}{ HER3 expression } & \multirow[b]{2}{*}{ P-value } \\
\hline & $\operatorname{High}(\mathrm{n}=30)$ & Low $(n=9)$ & \\
\hline Age (years) & $42.5(30-67)$ & $46.0(40-64)$ & 0.384 \\
\hline FIGO stage (2014) & & & 0.216 \\
\hline IB1 & $20(66.6)$ & $5(55.5)$ & \\
\hline IB2 & $8(26.6)$ & $2(22.2)$ & \\
\hline IIB & $2(6.6)$ & $2(22.2)$ & \\
\hline Histological type & & & 0.066 \\
\hline Adenocarcinoma & $23(76.6)$ & $4(44.4)$ & \\
\hline $\begin{array}{l}\text { Adenosquamous } \\
\text { carcinoma }\end{array}$ & $7(23.3)$ & $5(55.5)$ & \\
\hline Parametrial invasion & & & 0.311 \\
\hline Present & $8(26.7)$ & $4(44.4)$ & \\
\hline Absent & $22(73.3)$ & $5(55.5)$ & \\
\hline Vascular invasion & & & 0.134 \\
\hline 0 & $13(43.3)$ & $3(33.3)$ & \\
\hline 1 & $13(43.3)$ & $5(55.5)$ & \\
\hline 2 & $3(10.0)$ & $1(11.1)$ & \\
\hline 3 & $1(3.3)$ & $0(0.0)$ & \\
\hline Tumor size (cm) & & & 0.379 \\
\hline$\leq 4$ & $15(50.0)$ & $6(66.6)$ & \\
\hline$>4$ & $15(50.0)$ & $3(3.33)$ & \\
\hline Lymph node metastases & & & 0.047 \\
\hline Present & $21(70.0)$ & $3(33.3)$ & \\
\hline Absent & $9(30.0)$ & $6(66.6)$ & \\
\hline Treatment & & & 0.145 \\
\hline Surgery alone & $15(50.0)$ & $3(33.3)$ & \\
\hline $\begin{array}{l}\text { Surgery + adjuvant } \\
\text { radiation }\end{array}$ & $13(43.3)$ & $5(55.5)$ & \\
\hline $\begin{array}{l}\text { Surgery + adjuvant } \\
\text { chemoradiation }\end{array}$ & $2(6.6)$ & $1(11.1)$ & \\
\hline
\end{tabular}

Values are expressed as the median (range) or $\mathrm{n}(\%)$. FIGO, International Federation of Gynecology and Obstetrics; HER3, Erb-b2 receptor tyrosine kinase 3 .

vascular invasion $(\mathrm{HR}=4.28,95 \% \mathrm{CI}: 1.12-16.31, \mathrm{P}=0.033)$ were independent prognostic factors regarding DFS (Table III).

\section{Discussion}

The results of the present study suggested an association between the clinical outcomes of early-stage AC and ASC of the cervix and HER 3 expression. Although HER 3 expression did not exhibit any statistical significance on univariate Cox analysis for DFS, HER3 was a significant predictor on multivariate Cox analysis, indicating unfavorable DFS and OS prognosis. To the best of our knowledge, the present study was so far the largest to evaluate the expression of HER3 and its significance on post-operative recurrence in patients with early-stage AC and ASC of the cervix.
HER 3 is overexpressed in several cancer types and is associated with poor prognosis (20,31-38). HER3 promotes tumor initiation and progression, mainly through heterodimerization with receptor tyrosine kinases, to activate oncogenic signaling via the PI3K/AKT pathway. In addition, HER 3 expression and downstream PI3K/AKT signaling are major causes of treatment failure in cancer therapy due to their implication in therapeutic resistance (39). In the present study, HER3 expression was not a prognostic factor in the univariate Cox regression for DFS, on the other hand, HER3 overexpression appeared to be a poor prognostic factor for DFS in the multivariate Cox regression, along with pelvic lymph node metastasis and vascular invasion. This discrepancy between univariate and multivariate results can be attributed to the small number of cases and the resulting instability of the prognostic model. These results are still consistent with those of previous studies on patients with cervical cancer with SCC, in which HER3 was overexpressed in $74.4 \%(58 / 78)$ of patients and was associated with poor prognosis (22). In a study by Lee et al (23), 55 patients with FIGO IB-IVA cervical cancer, including 5 patients with AC and 2 with ASC, were evaluated for the expression of HER and phosphorylated AKT. However, the incidence of HER3 overexpression and its influence on survival among those populations were not presented, thereby remaining elusive. Therefore, the present study was the first to demonstrate the prognostic value of HER3 overexpression among patients with cervical AC and ASC. Due to the aforementioned discrepancy between the univariate and multivariate Cox regression model, the prognostic value of HER3 should be further verified in future studies. Combining the results of the present study with those obtained in previous studies, the incidence of HER3 overexpression was 55.6-74.4\% in patients with SCC, $85.1 \%$ in patients with AC and $58.3 \%$ in patients with ASC $(22,23)$. Whole-exome sequencing of primary frozen tumor tissues and the blood of patients with cervical cancer who did not receive any prior chemotherapy or radiotherapy indicated that the incidence of HER3 alterations was higher in patients with AC than in those with SCC (40). Several targeted therapies have been developed for HER3 and relevant studies indicate a possible therapeutic strategy for patients with cervical cancer expressing HER3 $(41,42)$.

Surgery and/or radiotherapy are highly effective for early-stage cervical cancer. However, patients with $\mathrm{AC}$ and ASC of the cervix are more resistant to radiotherapy than those with SCC $(16,19)$; therefore, novel therapies are required for patients with AC and ASC of the cervix. Recently, combination therapy with a dual antibody targeting both EGFR and HER 3 and enhanced ionizing radiation was reported to be effective (43). An additive effect was observed when the dual antibody, radiation and cisplatin were combined, leading to improved patient outcomes by increasing tumor control and by activating the immune response.

The human papillomavirus (HPV) is a carcinogenic virus in humans and has been implicated in cervical cancer (44). Among head and neck cancers, HER3 was overexpressed and highly bound to PI3K in HPV-positive tumors (45). In addition, a preclinical study by Brand et al (46) reported an association between HPV infection and HER3 in head and neck cancers, indicating that HPV-positive cancers were sensitive to HER3 
Table II. Expression score of HER3 in cervical adenocarcinoma and adenosquamous carcinoma.

\begin{tabular}{|c|c|c|c|c|c|c|}
\hline Histological type & $\mathrm{N}$ & 0 & $1+$ & $2+$ & $3+$ & $2+/ 3+$ \\
\hline Adenocarcinoma & 27 & $0(0.0)$ & $4(14.8)$ & $12(44.4)$ & $11(40.7)$ & $23(85.1)$ \\
\hline Adenosquamous carcinoma & 12 & $0(0.0)$ & $5(41.7)$ & $4(33.3)$ & $3(25.0)$ & $7(58.3)$ \\
\hline Total & 39 & $0(0.0)$ & $9(23.1)$ & $16(41.0)$ & $14(35.9)$ & $30(76.9)$ \\
\hline
\end{tabular}

Values are expressed as n (\%). HER3, Erb-b2 receptor tyrosine kinase 3.

Table III. Univariate and multivariate analysis of prognostic factors for disease-free survival.

\begin{tabular}{|c|c|c|c|c|c|c|}
\hline \multirow[b]{2}{*}{ Factor } & \multicolumn{2}{|c|}{ Univariate } & \multirow[b]{2}{*}{ P-value } & \multicolumn{2}{|c|}{ Multivariate } & \multirow[b]{2}{*}{ P-value } \\
\hline & HR & $95 \% \mathrm{CI}$ & & HR & $95 \% \mathrm{CI}$ & \\
\hline HER3 (high vs. low) & 2.54 & $0.57-11.31$ & 0.220 & 6.32 & $1.10-36.26$ & 0.039 \\
\hline Pelvic lymph node metastasis (present vs. absent) & 3.17 & $1.12-8.98$ & 0.030 & 7.61 & $2.07-28.00$ & 0.002 \\
\hline Tumor size $(\geq 4$ vs. $<4 \mathrm{~cm})$ & 1.67 & $0.60-4.63$ & 0.322 & 1.05 & $0.30-3.69$ & 0.942 \\
\hline Vascular invasion (present vs. absent) & 3.28 & $1.04-10.39$ & 0.043 & 4.28 & $1.12-16.31$ & 0.033 \\
\hline Parametrial invasion (present vs. absent) & 1.62 & $0.58-4.57$ & 0.361 & 0.68 & $0.18-2.59$ & 0.570 \\
\hline
\end{tabular}

HR, hazard ratio; HER3, Erb-b2 receptor tyrosine kinase 3.
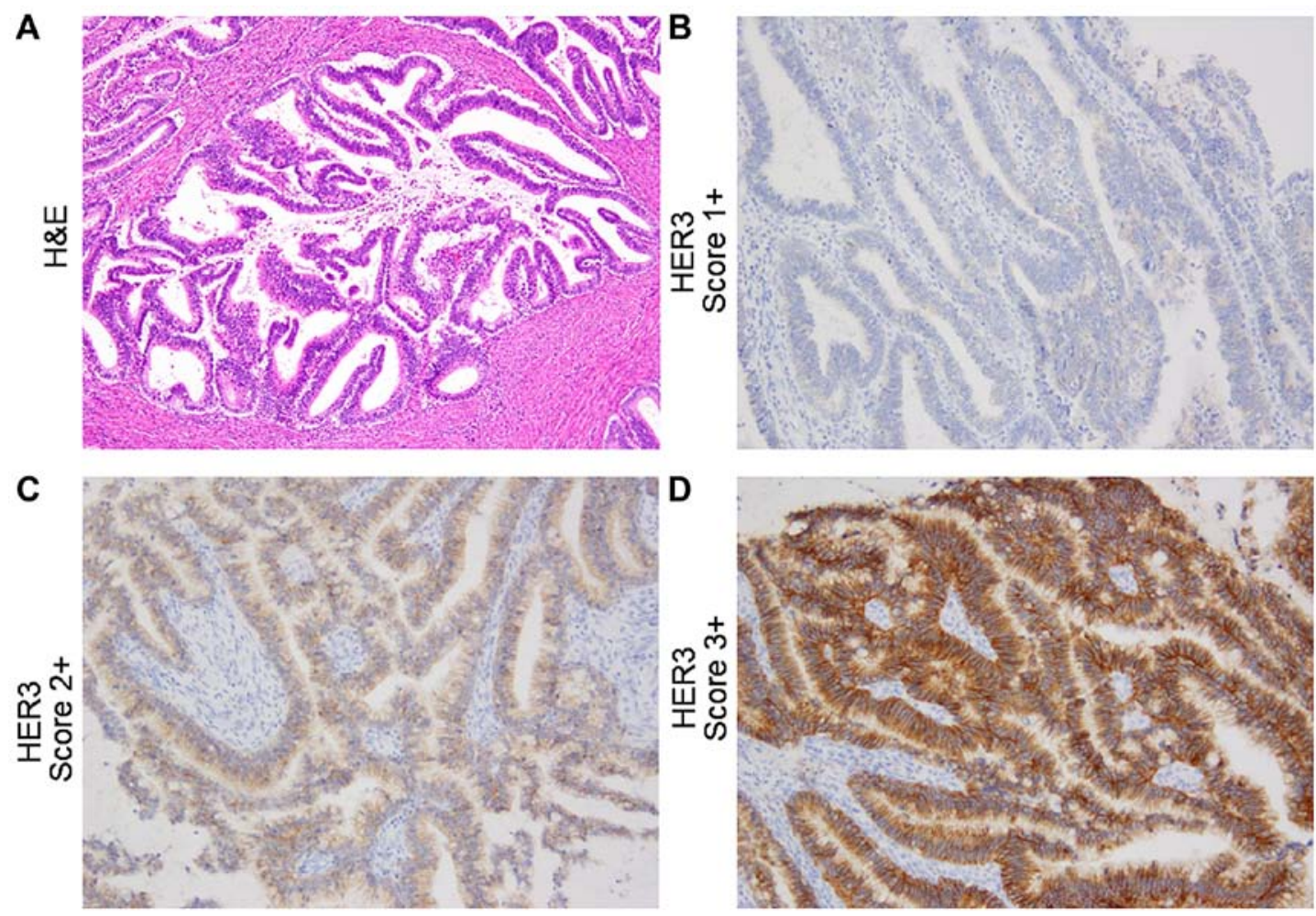

Figure 1. Representative histology images. (A) H\&E staining. (B-D) Immunohistochemical staining for HER3; (B) endocervical adenocarcinoma, usual type, pT1bN0, with HER3 score of 1+; (C) endocervical adenocarcinoma, usual type, pT2bN1, HER3 score of 2+; (D) endocervical adenocarcinoma, usual type, pT2bN1, HER3 score of 3+ (original magnification of all the histological images, x200). HER3 was predominantly expressed in the cytoplasm and on the membranes of tumor cells. HER3, Erb-b2 receptor tyrosine kinase 3; H\&E, hematoxylin and eosin.

targeting. By contrast, no association has been detected between HPV infection and HER in patients with cervical cancer. In the population included in the present study, the incidence of both HER3 and p16 expression was high and the correlation was not 
A

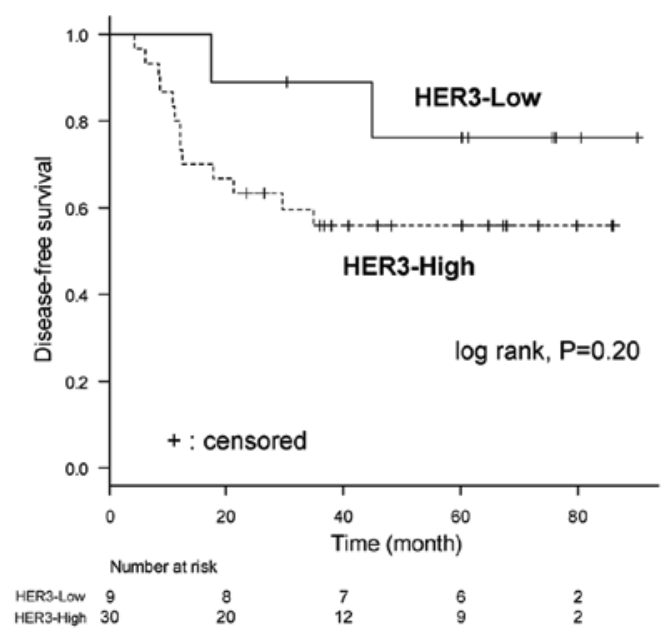

B

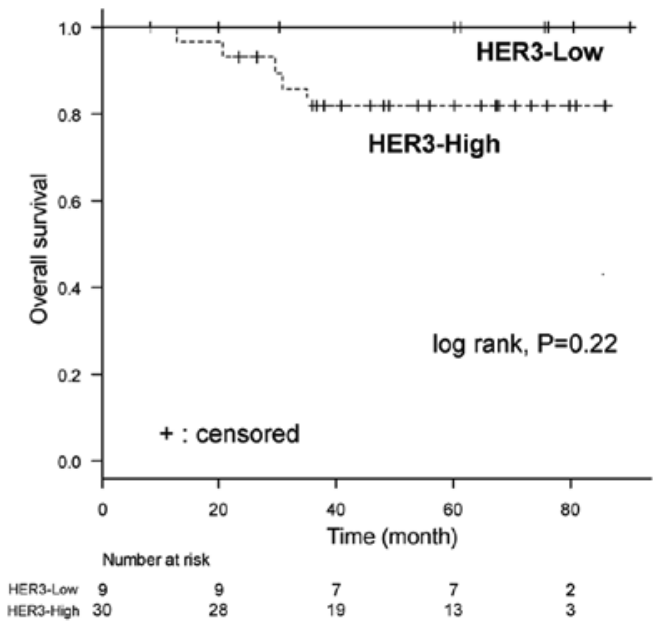

Figure 2. Kaplan-Meier curves for disease-free survival and overall survival depending on the status of HER3 expression. Kaplan-Meier curves for (A) disease-free survival and (B) overall survival of patients with metastatic disease with high HER3 expression (dashed line) and low HER3 expression (solid line). HER3, Erb-b2 receptor tyrosine kinase 3.

significant (data not shown). Accordingly, further studies are required to evaluate the etiology of HPV infection and HER3 expression in patients with cervical cancer.

The present study has several limitations; it was a retrospective study in a single institution and included a small number of patients with AC and ASC in the cervix. In addition, as the enrollement period was long, the treatment strategy varied over the decades. Hence, further study is required to evaluate the role of HER 3 in the current era of precision medicine, during which several HER3-targeting drugs are being developed (47-49). In the present study, the DFS of patients who underwent surgery was evaluated, which is an important factor for such patients; however, the influence of HER3 on OS remains undetermined due to the small number of patients who died. Furthermore, even though most of the study population was positive for p16, no significant correlation between p16 and HER3 was determined. Accordingly, future studies are required to determine the etiology of HPV infection and HER3 expression in patients with cervical cancer.

In conclusion, the results of the present study indicated that the expression of HER3 was associated with poor DFS in patients with early-stage AC and ASC of the cervix; therefore, HER3 expression may be a novel prognostic biomarker. However, further studies are required to confirm these results and the prognostic value of HER3.

\section{Acknowledgements}

The authors would like to thank Ms. Nao Nakamura and Ms. Kotone Shoji, Department of Breast and Medical Oncology, National Cancer Center Hospital (Tokyo, Japan) for their secretarial assistance.

\section{Funding}

The National Cancer Center Biobank is supported by the National Cancer Center Research and Development Fund, Japan.

\section{Availability of data and materials}

The datasets used during the present study are available from the corresponding author upon reasonable request.

\section{Authors' contributions}

TM, YK, KY, HY, YS, YoO, HSO, TN, MT, KS, AS, EN, TK, TS, MU, MI, YF, YuO and KT were responsible for the conception and design of the present study, drafted the manuscript, were responsible for the collection and assembly of the data, performed the data analysis and interpretation, and read, revised and approved the final manuscript. All authors are in agreement to be accountable for all aspects of the work in ensuring that questions related to the accuracy or integrity of any part of the work are appropriately investigated and resolved.

\section{Ethics approval and consent to participate}

The present study was approved by the Ethics Committee of the National Cancer Center Hospital (Tokyo, Japan; approval no. 2014-393). Written informed consent was obtained from all patients.

\section{Patient consent for publication}

Not applicable.

\section{Competing interests}

The authors declare that they have no competing interests.

\section{References}

1. Bray F, Ferlay J, Soerjomataram I, Siegel RL, Torre LA and Jemal A: Global cancer statistics 2018: GLOBOCAN estimates of incidence and mortality worldwide for 36 cancers in 185 countries. CA Cancer J Clin 68: 394-424, 2018. 
2. Center for Cancer Control and Information Services, National Cancer Center: Cancer Registry and Statistics. https://ganjoho.jp/ reg stat/statistics/dl/index.html. Accessed March 11, 2016.

3. Castanon A, Landy R and Sasieni PD: Is cervical screening preventing adenocarcinoma and adenosquamous carcinoma of the cervix? Int J Cancer 139: 1040-1045, 2016.

4. Sasieni $\mathrm{P}$ and Adams J: Changing rates of adenocarcinoma and adenosquamous carcinoma of the cervix in England. Lancet 357: $1490-1493,2001$

5. Galic V, Herzog TJ, Lewin SN, Neugut AI, Burke WM, Lu YS, Hershman DL and Wright JD: Prognostic significance of adenocarcinoma histology in women with cervical cancer. Gynecol Oncol 125: 287-291, 2012.

6. Park JY, Kim DY, Kim JH, Kim YM, Kim YT and Nam JH: Outcomes after radical hysterectomy in patients with early-stage adenocarcinoma of uterine cervix. Br J Cancer 102: 1692-1698, 2010.

7. Lee YY, Choi CH, Kim TJ, Lee JW, Kim BG, Lee JH and Bae DS: A comparison of pure adenocarcinoma and squamous cell carcinoma of the cervix after radical hysterectomy in stage IB-IIA. Gynecol Oncol 120: 439-443, 2011.

8. Mabuchi S, Okazawa M, Matsuo K, Kawano M, Suzuki O, Miyatake T, Enomoto T, Kamiura S, Ogawa K and Kimura T: Impact of histological subtype on survival of patients with surgically-treated stage IA2-IIB cervical cancer: Adenocarcinoma versus squamous cell carcinoma. Gynecol Oncol 127: 114-20, 2012.

9. Shingleton HM, Bell MC, Fremgen A, Chmiel JS, Russell AH, Jones WB, Winchester DP and Clive RE: Is there really a difference in survival of women with squamous cell carcinoma, adenocarcinoma, and adenosquamous cell carcinoma of the cervix? Cancer 76 (10 Suppl): 1948-1955, 1995.

10. Farley JH, Hickey KW, Carlson JW, Rose GS, Kost ER and Harrison TA: Adenosquamous histology predicts a poor outcome for patients with advanced-stage, but not early-stage, cervical carcinoma. Cancer 97: 2196-2202, 2003.

11. Lea JS, Coleman RL, Garner EO, Duska LR, Miller DS and Schorge JO: Adenosquamous histology predicts poor outcome in low-risk stage IB1 cervical adenocarcinoma. Gynecol Oncol 91: 558-562, 2003.

12. dos Reis R, Frumovitz M, Milam MR, Capp E, Sun CC, Coleman RL and Ramirez PT: Adenosquamous carcinoma versus adenocarcinoma in early-stage cervical cancer patients undergoing radical hysterectomy: An outcomes analysis. Gynecol Oncol 107: 458-463, 2007.

13. Mabuchi S, Okazawa M, Kinose Y, Matsuo K, Fujiwara M, Suzuki O, Morii E, Kamiura S, Ogawa K and Kimura T: Comparison of the prognoses of FIGO stage I to stage II adenosquamous carcinoma and adenocarcinoma of the uterine cervix treated with radical hysterectomy. Int J Gynecol Cancer 22: $1389-1397,2012$.

14. Noh JM, Park W, Kim YS, Kim JY, Kim HJ, Kim J, Kim JH Yoon MS, Choi JH, Yoon WS, et al: Comparison of clinical outcomes of adenocarcinoma and adenosquamous carcinoma in uterine cervical cancer patients receiving surgical resection followed by radiotherapy: A multicenter retrospective study (KROG 13-10). Gynecol Oncol 132: 618-623, 2014.

15. Huang YT, Wang CC, Tsai CS, Lai CH, Chang TC, Chou HH, Lee SP and Hong JH: Clinical behaviors and outcomes for adenocarcinoma or adenosquamous carcinoma of cervix treated by radical hysterectomy and adjuvant radiotherapy or chemoradiotherapy. Int J Radiat Oncol Biol Phys 84: 420-427, 2012

16. Rose PG, Java JJ, Whitney CW, Stehman FB, Lanciano R and Thomas GM: Locally advanced adenocarcinoma and adenosquamous carcinomas of the cervix compared to squamous cell carcinomas of the cervix in gynecologic oncology group trials of cisplatin-based chemoradiation. Gynecol Oncol 135: 208-212, 2014.

17. Winer I, Alvarado-Cabrero I, Hassan O, Ahmed QF, Alosh B, Bandyopadhyay S, Thomas S, Albayrak S, Talukdar S, Al-Wahab Z, et al: The prognostic significance of histologic type in early stage cervical cancer-A multi-institutional study. Gynecol Oncol 137: 474-478, 2015.

18. Cao L, Wen H, Feng Z, Han X and Wu X: Distinctive clinicopathologic characteristics and prognosis for different histologic subtypes of early cervical cancer. Int J Gynecol Cancer 29: 1244-1251, 2019.

19. Chen JL, Huang CY, Huang YS, Chen RJ, Wang CW, Chen YH, Cheng JC, Cheng AL and Kuo SH: Differential clinical characteristics, treatment response and prognosis of locally advanced adenocarcinoma/adenosquamous carcinoma and squamous cell carcinoma of cervix treated with definitive radiotherapy. Acta Obstet Gynecol Scand 93: 661-668, 2014.
20. Plowman GD, Whitney GS, Neubauer MG, Green JM, McDonald VL, Todaro GJ and Shoyab M: Molecular cloning and expression of an additional epidermal growth factor receptor-related gene. Proc Natl Acad Sci USA 87: 4905-4909, 1990.

21. Li Q, Zhang R, Yan H, Zhao P, Wu L, Wang H, Li T and Cao B: Prognostic significance of HER3 in patients with malignant solid tumors. Oncotarget 8: 67140-67151, 2017.

22. Fuchs I, Vorsteher N, Buhler H, Evers K, Sehouli J, Schaller G and Kümmel S: The prognostic significance of human epidermal growth factor receptor correlations in squamous cell cervical carcinoma. Anticancer Res 27: 959-963, 2007.

23. Lee CM, Shrieve DC, Zempolich KA, Lee RJ, Hammond E, Handrahan DL and Gaffney DK: Correlation between human epidermal growth factor receptor family (EGFR, HER2, HER3, HER4), phosphorylated Akt (P-Akt), and clinical outcomes after radiation therapy in carcinoma of the cervix. Gynecol Oncol 99: 415-421, 2005.

24. FIGO Committee on Gynecologic Oncology: FIGO staging for carcinoma of the vulva, cervix, and corpus uteri. Int J Gynaecol Obstet 125: 97-98, 2014

25. Bartley AN, Washington MK, Colasacco C, Ventura CB, Ismaila N, Benson AB III, Carrato A, Gulley ML, Jain D, Kakar S, et al: HER2 testing and clinical decision making in gastroesophageal adenocarcinoma: Guideline From the College of American Pathologists, American Society for Clinical Pathology, and American Society of Clinical Oncology. Arch Pathol Lab Med 140: 1345-1363, 2016.

26. Kurman RJ, Carcangiu ML and Herrington CS: World Health Organization classification of tumours of female reproductive organs. 4th ed. Geneva: WHO Press, 2014.

27. Ryu SY, Kim MH, Nam BH, Lee TS, Song ES, Park CY, Kim JW, Kim YB, Ryu HS, Park SY, et al: Intermediate-risk grouping of cervical cancer patients treated with radical hysterectomy: A Korean gynecologic oncology group study. $\mathrm{Br} \mathbf{J}$ Cancer 110: 278-285, 2014.

28. Kim MK, Jo H, Kong HJ, Kim HC, Kim JW, Kim YM, Song YS, Kang SB, Mok JE and Lee HP: Postoperative nomogram predicting risk of recurrence after radical hysterectomy for early-stage cervical cancer. Int J Gynecol Cancer 20: 1581-1386, 2010.

29. Wang H,Zhu L, Lu W, Xu H, Yu Y and Yang Y: Clinicopathological risk factors for recurrence after neoadjuvant chemotherapy and radical hysterectomy in cervical cancer. World J Surg Oncol 11: 301, 2013

30. Kanda Y: Investigation of the freely available easy-to-use software 'EZR' for medical statistics. Bone Marrow Transplant 48: 452-458, 2013

31. Tanner B, Hasenclever D, Stern K, Schormann W, Bezler M, Hermes M, Brulport M, Bauer A, Schiffer IB, Gebhard S, et al: ErbB-3 predicts survival in ovarian cancer. J Clin Oncol 24: 4317-4323, 2006

32. Witton CJ, Reeves JR, Going JJ, Cooke TG and Bartlett JM: Expression of the HER1-4 family of receptor tyrosine kinases in breast cancer. J Pathol 200: 290-297, 2003.

33. Yi ES, Harclerode D, Gondo M, Stephenson M, Brown RW, Younes $\mathrm{M}$ and Cagle PT: High c-erbB-3 protein expression is associated with shorter survival in advanced non-small cell lung carcinomas. Mod Pathol 10: 142-148, 1997.

34. Reschke M, Mihic-Probst D, van der Horst EH, Knyazev P, Wild PJ, Hutterer M, Meyer S, Dummer R, Moch H and Ullrich A: HER3 is a determinant for poor prognosis in melanoma. Clin Cancer Res 14: 5188-5197, 2008.

35. Bae SY, La Choi Y, Kim S, Kim M, Kim J, Jung SP, Choi MY, Lee SK, Kil WH, Lee JE and Nam SJ: HER3 status by immunohistochemistry is correlated with poor prognosis in hormone receptor-negative breast cancer patients. Breast Cancer Res Treat 139: 741-750, 2013.

36. Ledel F, Hallstrom M, Ragnhammar P, Ohrling K and Edler D: HER3 expression in patients with primary colorectal cancer and corresponding lymph node metastases related to clinical outcome. Eur J Cancer 50: 656-662, 2014.

37. Qian G, Jiang N, Wang D, Newman S, Kim S, Chen Z, Garcia G, MacBeath G, Shin DM, Khuri FR, et al: Heregulin and HER3 are prognostic biomarkers in oropharyngeal squamous cell carcinoma. Cancer 121: 3600-3611, 2015

38. Ema A, Yamashita K, Ushiku H, Kojo K, Minatani N, Kikuchi M, Mieno H, Moriya H, Hosoda K, Katada N, et al: Immunohistochemical analysis of RTKs expression identified HER3 as a prognostic indicator of gastric cancer. Cancer Sci 105: 1591-1600, 2014. 
39. Amin DN, Campbell MR and Moasser MM: The role of HER3, the unpretentious member of the HER family, in cancer biology and cancer therapeutics. Semin Cell Dev Biol 21: 944-950, 2010.

40. Cancer Genome Atlas Research Network: Integrated genomic and molecular characterization of cervical cancer. Nature 543: 378-384, 2017.

41. Jaiswal BS, Kljavin NM, Stawiski EW, Chan E, Parikh C Durinck S, Chaudhuri S, Pujara K, Guillory J, Edgar KA, et al: Oncogenic ERBB3 mutations in human cancers. Cancer Cell 23 603-617, 2013.

42. Karachaliou N, Lazzari C, Verlicchi A, Sosa AE and Rosell R: HER3 as a therapeutic target in cancer. BioDrugs 31: 63-73, 2017.

43. Bourillon L, Demontoy S, Lenglet A, Zampieri A, Fraisse J, Jarlier M, Boissière-Michot F, Perrochia H, Rathat G, Garambois V, et al: Higher anti-tumor efficacy of the dual HER3-EGFR Antibody MEHD7945a combined with ionizing irradiation in cervical cancer cells. Int J Radiat Oncol Biol Phys 106: 1039-1051, 2020.

44. Crosbie EJ, Einstein MH, Franceschi S and Kitchener HC: Human papillomavirus and cervical cancer. Lancet 382: 889-899, 2013.

45. Pollock NI, Wang L, Wallweber G, Gooding WE, Huang W, Chenna A, Winslow J, Sen M, DeGrave KA, Li H, et al: Increased expression of HER 2, HER 3, and HER 2:HER3 heterodimers in HPV-Positive HNSCC using a novel proximity-based assay: implications for targeted therapies. Clin Cancer Res 21 : 4597-4606, 2015.
46. Brand TM, Hartmann S, Bhola NE, Peyser ND, Li H, Zeng Y, Isaacson Wechsler E, Ranall MV, Bandyopadhyay S, Duvvuri U, et al: Human papillomavirus regulates HER3 expression in head and neck cancer: Implications for targeted HER3 therapy in HPV $(+)$ Patients. Clin Cancer Res 23: 3072-3083, 2017.

47. Liu JF, Ray-Coquard I, Selle F, Poveda AM, Cibula D, Hirte H, Hilpert F, Raspagliesi F, Gladieff L, Harter P, et al: Randomized phase II trial of seribantumab in combination with paclitaxel in patients with advanced platinum-resistant or -refractory ovarian cancer. J Clin Oncol 34: 4345-4353, 2016.

48. Kogawa T, Yonemori K, Masuda N, Takahashi S, Takahashi M, Iwase H, Nakayama T, Saeki T, Toyama T, Takano T, et al: Single agent activity of U3-1402, a HER3-targeting antibody-drug conjugate, in breast cancer patients: Phase 1 dose escalation study. J Clin Oncol 36 (Suppl 15): 2512, 2018.

49. Janne PA, Yu HA, Johnson ML, Steuer CE, Vigliotti M, Iacobucci C, Chen S, Yu C, Dalila B. Sellami DB; Dana-Farber Cancer Institute; Memorial Sloan Kettering Cancer Center; Sarah Cannon Research Institute; Winship Cancer Institute of Emory University; Daiichi Sankyo, Inc.: Safety and preliminary antitumor activity of U3-1402: A HER3-targeted antibody drug conjugate in EGFR TKI-resistant, EGFRm NSCLC. J Clin Oncol 37 (Suppl 15): 9010, 2019.

This work is licensed under a Creative Commons

Attribution-NonCommercial-NoDerivatives 4.0 International (CC BY-NC-ND 4.0) License. 